\title{
Evaluating different harvest intensities over understory plant diversity and pine seedlings, in a Pinus pinaster Ait. natural stand of Spain
}

\author{
Josu González-Alday ${ }^{1}$, Carolina Martínez-Ruiz ${ }^{1}$ and Felipe Bravo \\ ${ }^{1}$ Departamento de Ecología. E.T.S. de Ingenierías Agrarias. Universidad de Valladolid. Avenida de Madrid, 44. \\ 34004. Palencia, Spain. Corresponding author e-mail address: josucham@gmail.com \\ 2 Departamento de Producción Vegetal y Recursos Forestales. E.T.S. de Ingenierías Agrarias. Universidad de \\ Valladolid. Avenida de Madrid, 44. 34004. Palencia, Spain.
}

\begin{abstract}
Although modern forestry takes into consideration the analysis of the effects of forest management on plant structure, diversity and seedlings, little is known about how those parameters respond to harvest techniques in the Mediterranean region. We investigated the effect of three different harvest intensities, respect to uncut controls, on understory plant species functional groups, richness, diversity and pine seedlings in a natural Maritime pine stand in Spain, three years after harvesting. The harvest treatments produced a reduction of the number of Pinus pinaster seedlings and woody species cover, and an increase of species richness (total and of annual species) and plant cover of annual species respect to control plots (CO). The Shannon diversity values showed no differences between treatments. These results emphasize that the tree harvest treatments analyzed are not suitable for the management of this Pinus pinaster stand. Otherwise, the reduction of pine seedling density by harvest treatments and the changes in richness and cover of functional groups would not induce the natural regeneration of this stand maintaining the understory plant layer.
\end{abstract}

Key words: Anthropogenic disturbance/ Herbaceous layer/ Mediterranean ecosystem/ Silviculture/ Woody species.

This is a pre-copyedited, author-produced PDF of an article published in 2009 in Plant Ecology. The final publication: Volume 201, Issue 1, pp 211-220 is available at Springer via: http://link.springer.com/article/10.1007/s11258-008-9490-2 


\section{INTRODUCCION}

One of the major challenges for modern forestry is to combine conservation of biodiversity and ecosystem functioning with wood production and other values (Hummel 2003; Decocq et al. 2004; Nagai \& Yoshida 2006; Newmaster et al. 2007). These general principles will obviously need to be achieved using adequate management practices (Kimmins 2004). It is generally assumed that management practices, and especially harvesting, modulate simultaneously the availability of different types of resources (e.g. light, water and soil nutrients; Decocq et al. 2004). As a result, understory species diversity and flora, which play a fundamental role in the structure and function of ecosystems (Roberts \& Gilliam 1995; Newmaster et al. 2007), become quite affected (Hughes \& Fahey 1991; Zenner et al. 2006). Therefore, the knowledge of the effects of different harvest disturbances on understory plant layer is an essential element to implement sustainable management of forest landscapes (Halpern \& Spies 1995; Roberts \& Gilliam 1995; Fahey \& Puettmann 2007).

Maritime pine (Pinus pinaster Ait.) is a natural forest species characteristic of the western Mediterranean basin, mainly distributed over the Iberian Peninsula, France and Italy (Alía et al. 1996). Traditionally, P. pinaster in central Spain has been used for resin production and soil protection against mobile continental dunes (Bravo-Oviedo et al. 2007), with wood production as secondary objective. An important step towards ecologically sound wood production procedures is to test different management alternatives (i.e. harvest intensities) to induce the natural revegetation of these stands. At the same time, these alternatives should always contribute to maintain the landscape and ecological protection functions, mushrooms production and biodiversity of the stands (Oria de Rueda 2003), while sustainable wood and resin production is obtained.

The effect of forest management on plant diversity and flora is complex and more difficult to generalize than it was originally thought (Tárrega et al. 2006), underlining the importance of studying plant and diversity responses for different forest types and harvest techniques (Gilliam 2002). Moreover, most published studies concern managed forests in North America, whose history and tradition radically differ from Europe (Decocq et al. 2004), and particularly from the Mediterranean region (ScarasciaMugnozza et al. 2000). The aim of this study, therefore, is to investigate the effects of three harvest intensities, relative to untreated control areas, on understory species richness, diversity, functional groups (life forms) and $P$. pinaster seedlings, and their 
relation to the remaining basal area and canopy cover of a natural maritime pine stand in semi-arid Mediterranean conditions in Spain, three years after harvest. We hypothesized that: (1) the number of $P$. pinaster seedlings in such semi-arid Mediterranean conditions would be reduced by harvest intensity, (2) the functional groups (annual and perennial herbs and woody species) cover and richness would be affected by harvest treatments, and (3) the understory plant richness and diversity would be markedly affected by harvest intensity.

\section{METHODS}

\subsection{Study area}

This study was conducted in a flat natural Maritime pine forest located in the

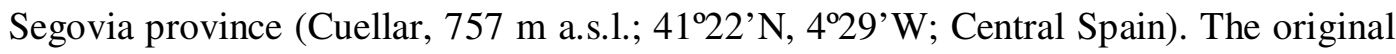
stand density was 140 stems/ha, tree age ranges from 80 to 100 years and silvicultural practice is based on natural regeneration following a shelterwood system adapted to resin production. The climate is semi-arid Mediterranean, with a mean annual temperature of $11.2{ }^{\circ} \mathrm{C}$, a mean annual rainfall of $461 \mathrm{~mm}$ and dry period from the middle of June to the middle of September (M.A.P.A. 1987). The soils are sandy siliceous of Quaternary age (Junta de Castilla y León 1988), and the vegetation of the area is dominated by Pinus pinaster with some isolated trees of stone pine (Pinus pinea L.) and crop fields.

\subsection{Treatments}

About 16 continuous hectares of natural Maritime pine were selected in a ca. 15,000 ha of forest to delimit twelve $70 \times 70 \mathrm{~m}$ permanent plots. To record the variation caused by silviculture treatments rather than to site variability, the selected hectares shared the same abiotic conditions, forest structure and vegetation composition. After plots were established two variables were recorded for all trees with diameter at breast height greater than $7.5 \mathrm{~cm}$ found inside the plots: diameter at breath height $(\mathrm{DBH} ; \mathrm{cm})$, and crown diameters $(\mathrm{m})$. The $\mathrm{DBH}$ and crown diameters were measured in order to obtain the basal area (BA) and the canopy cover (\%) as informative parameters of the light conditions for ground vegetation (Härdtle et al. 2003). Three levels of harvest intensity with three replicates for each one were applied over nine of the permanent plots: (1) $25 \%$ of basal area removed (close plots, H25), (2) $50 \%$ of basal area removed (open plots, H50), and (3) 100\% of basal area removed (clear-cut plots; CC). All treatments were randomly allocated on these nine plots, whereas the remaining three 
permanent plots were used as control units $(\mathrm{CO})$ not receiving any treatment during the study. Harvesting was carried out manually with handsaw once all trees selected for cutting were marked according to the basal area removal criteria. The trees were harvested using a silvicultural criterion to facilitate the natural regeneration, i.e. trees showing disease or physical damage were removed first, followed by the smaller trees and finally by others with larger diameters, to increase the amounts of low- and midstory shade. Moreover, harvesting was designed to distribute residual overstory canopies as uniform as possible inside every particular harvest plot (H25, H50). The sampling of DBH and crown diameters was carried out in summer 2003, whereas the harvest operations were made in autumn 2003.

\subsection{Understory vegetation sampling}

To sample understory vegetation in each of 12 permanent plots, 20 quadrats of $1 \times 1 \mathrm{~m}$ were placed using simple random sampling design (Krebs 1999). However, in order to evade edge effect the first $10 \mathrm{~m}$ from the plot edge were avoided. In each quadrat, the cover $(\%)$ of all vascular plant species present and the number of $P$. pinaster seedlings (criteria = maximum 3 -years old) were estimated visually by the same observer in May 2006.

\subsection{Data analysis}

Diversity of understory plant communities was assessed using the Shannon index (H') (Shannon \& Weaver 1949) with logs to base 2, and its two components, richness (S) and evenness (J') (Pielou 1969). Shannon diversity and richness were calculated both on two scales, similar to Tárrega et al. (2006): (i) on small scale (per

quadrat or $\mathrm{m}^{2}$ ), alpha diversity or microcosmic diversity (Magurran 2004); and (ii) on a community scale for each plot $\left(4,900 \mathrm{~m}^{2}\right)$, plot gamma diversity or macrocosmic diversity (from the joint consideration of the 20 samples carried out for each study plot). Evenness, however, was calculated only on a community scale. By using the comparison of both types of diversity, beta diversity or spatial heterogeneity was calculated: $S_{\beta}$ by the Whittaker (in Magurran 2004) formula, $S_{\beta}=\left(S / S_{\alpha}\right)-1$, and $H^{\prime}{ }_{\beta}$ as the difference between $\mathrm{H}^{\prime}$ and the average of $\mathrm{H}_{\alpha}^{\prime}$ (Margalef 1972). The number of $P$. pinaster seedlings is referred to the total number of seedlings in the 20 quadrats of each plot.

To evaluate the significance of different harvest treatments, relative to a controls, on the number of $P$. pinaster seedlings, functional groups cover (annual herbs, 
perennial herbs and woody species), species richness (S), evenness (J') and diversity values $\left(\mathrm{H}^{\prime}{ }_{\alpha}, \mathrm{H}^{\prime}, \mathrm{H}^{\prime}{ }_{\beta}, \mathrm{S}_{\alpha}\right.$ and $\mathrm{S}_{\beta}$ ), one-way analyses of variance (ANOVA) were applied followed by Tukey's HSD tests to enable pairwise comparisons of means $(p<0.05)$. In all cases, the inspection of residuals was carried out to check for normality and homoscedasticity. Nevertheless, when variables not meet normality and variance assumptions data were transformed using arcsine squared-root transformation for binomially distributed variables (i.e. plant cover) and squared-root transformation for count data (i.e. richness) (Zar 1996).

In order to determine possible relationships among the 13 variables analyzed, a Pearson's correlation matrix was constructed considering: canopy cover, basal area, number of $P$. pinaster seedlings, number of woody species, number of perennial and annual herbs and J', $\mathrm{H}_{\alpha}^{\prime}, \mathrm{H}_{\beta}{ }_{\beta}, \mathrm{H}^{\prime}, \mathrm{S}_{\alpha}, \mathrm{S}_{\beta}$ and $\mathrm{S}$. A Principal components analysis (PCA) was used to summarise the relationships among treatments and the variables as a whole. Data for the 13 variables used in PCA were standardized prior to analysis to correct for different measuring units.

Results were expressed as mean \pm standard error and all statistical computations were implemented in the $\mathrm{R}$ software environment (version 2.7.0; $\mathrm{R}$ Development Core Team 2008).

\section{RESULTS}

\subsection{P. pinaster seedlings}

The density of $P$. pinaster seedlings found in the plots was lower than 3.3 seedlings $/ \mathrm{m}^{2}$, however significant differences among harvest intensities were found $\left(F_{[3,8]}=23.4, p<0.001\right.$; Fig. 1). Untreated control plots $(\mathrm{CO})$ showed the greatest number of seedlings ( $66 \pm 13.5)$, clear cut plots (CC) the lowest $(1 \pm 0.58)$, and H25 and $\mathrm{H} 50$ treated plots an intermediate number of them (16 \pm 8.5 and $8 \pm 1.8$, respectively). 


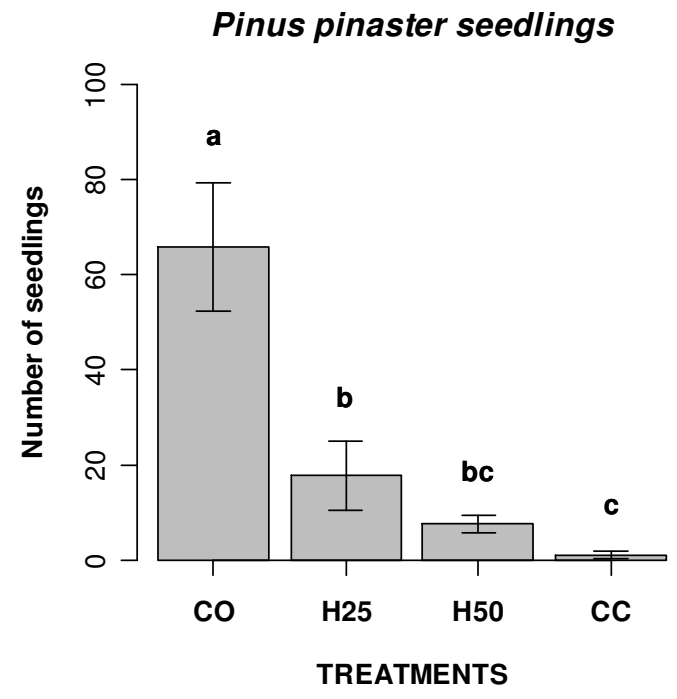

Figure 1. Comparison of the number of $P$. pinaster seedlings (per $20 \mathrm{~m}^{2}$ ) among treatments (mean $\pm \mathrm{SE}$ ). CO: control plots; H25: 25\% of basal area removed (close plots); H50: 50\% of basal area removed (open plots); CC: $100 \%$ of basal area removed (clear cut). Different letters above the bars indicate significant differences $(p<0.05)$ by Tukey's test.

\subsection{Functional groups (life forms)}

Annual species dominated, in number and cover, the understory plant communities in the four treatments (Fig. 2). Annual cover was similar in the tree treated areas (H25, H50 and CC), ranging between 37 and 41\%, and significantly greater than in the untreated $\mathrm{CO}\left(F_{[3,8]}=16.59, p<0.001\right.$; Fig. 2a). On the contrary, the cover of woody species was significantly greater in the $\mathrm{CO}$ than in the $\mathrm{CC}$ and open plots (H50) $\left(F_{[3,8]}=7.01, p=0.013\right)$, where it hardly reached a $2 \%$. The cover of perennial herbs only differed between the $\mathrm{CC}$ and open plots $(\mathrm{H} 50)\left(F_{[3,8]}=5.36, p=0.026\right)$.

Annual species number significantly varied with harvest intensity. Clear cut plots (CC), with maximum values (41 \pm 1.78$)$, followed by open plots $(\mathrm{H} 50 ; 31 \pm 0.33$ ) showed significantly greater values than control plots $(\mathrm{CO})\left(F_{[3,8]}=23.21, p<0.001\right.$; Fig. 2b). Perennial species number was also significantly greater in the clear cut plots (CC) than in the rest $\left(F_{[3,8]}=7.3, p=0.011\right.$; Fig. $\left.2 b\right)$, whereas the number of woody species did not differ with harvest intensity $\left(F_{[3,8]}=0.58, p=0.647\right)$. 
a) Plant cover

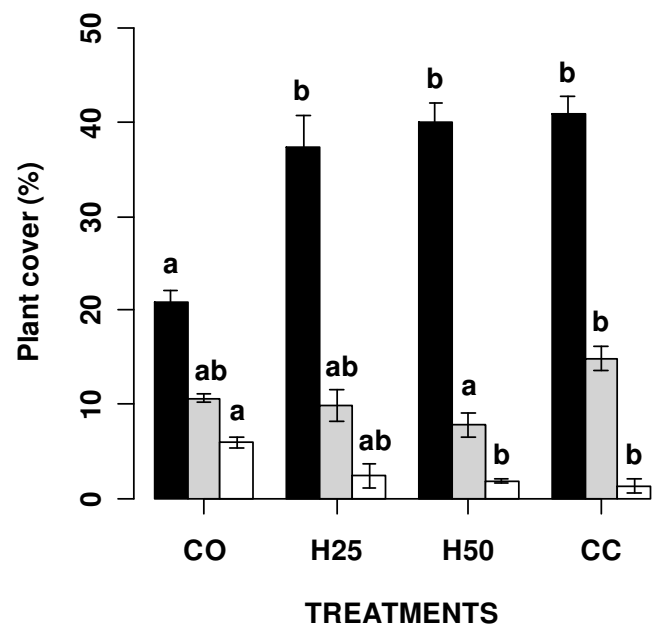

b) Species richness

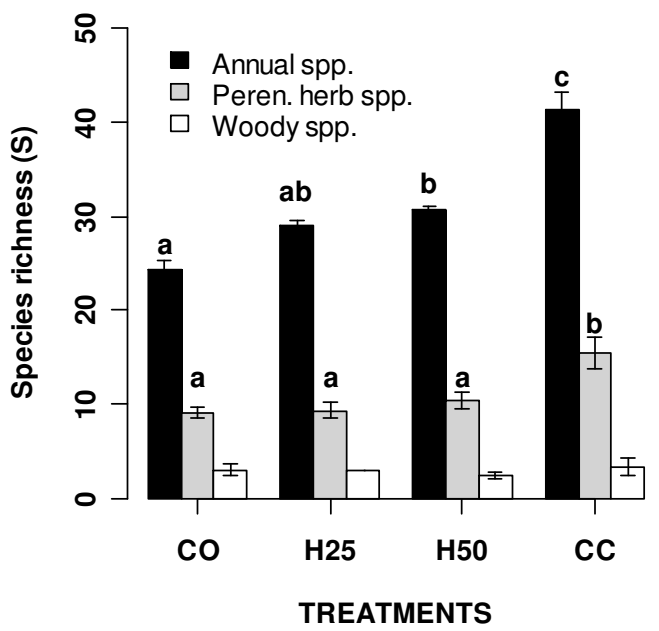

Figure 2. Comparison of annual, perennial herbaceous and woody species cover and richness among treatments (mean $\pm \mathrm{SE}$ ). See Methods or Figure 1 caption for treatment description. Different letters above the bars indicate significant differences among treatments $(p<0.05)$ by Tukey's test.

\subsection{Richness and diversity}

The small scale richness $\left(S_{\alpha}\right)$ varied between 12 and 17 species $/ \mathrm{m}^{2}$ in control and clear cut plots, respectively, but not differed significantly among treatments $\left(F_{[3,8]}=\right.$ 2.54, $p=0.130$; Fig. 3a). In contrast, species richness on a community scale (S), which ranged between 37 and 62 species per treatment, showed significantly greater values in clear cut plots $(\mathrm{CC})$ than in the remainder $\left(F_{[3,8]}=16.86, p<0.001\right.$; Fig. $\left.3 \mathrm{a}\right)$. In spite of that, Shannon diversity index, which showed high values in the four treatments $\left(\mathrm{H}^{\prime}\right.$ always above 4.2; Fig. $3 b)$, did not differ significantly with harvest intensity $\left(F_{[3,8]}=\right.$ $0.28, p=0.835$ ), due to a reduction of evenness, though not statistically significant, in the treated plots (H25, H50 and CC) in comparison with controls (CO; Fig. 3d). There were no significant differences in spatial heterogeneity among harvest intensities (Fig. $3 c)$. 
a)
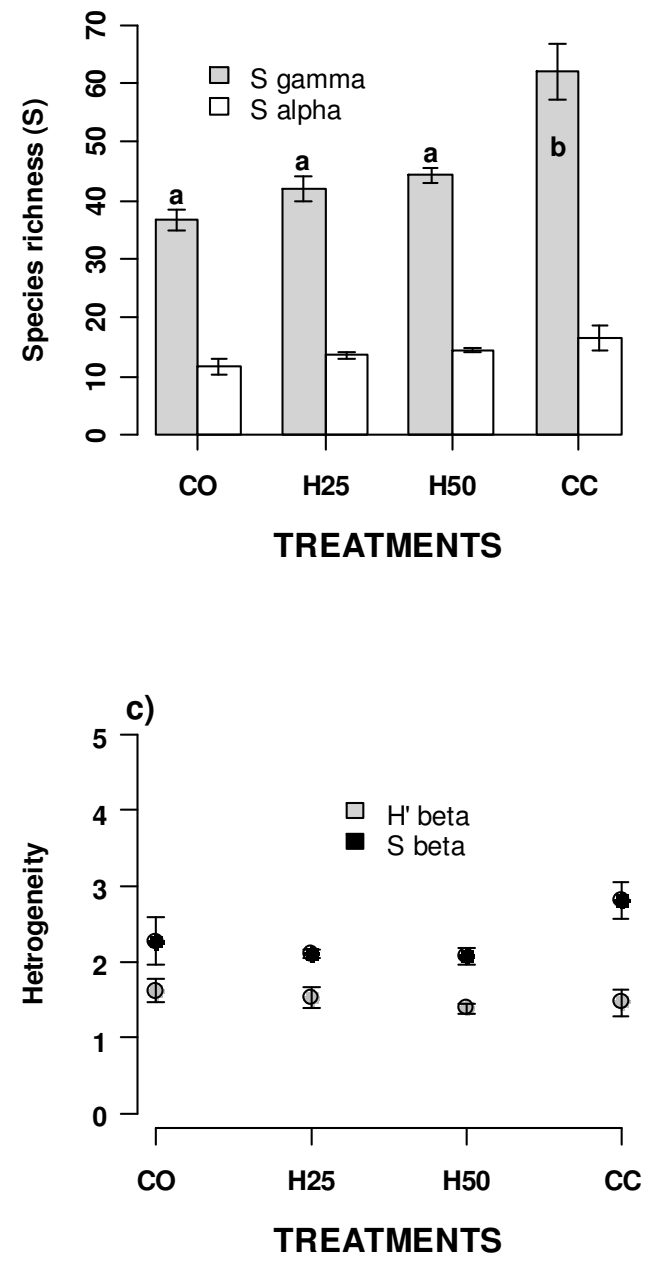

b)

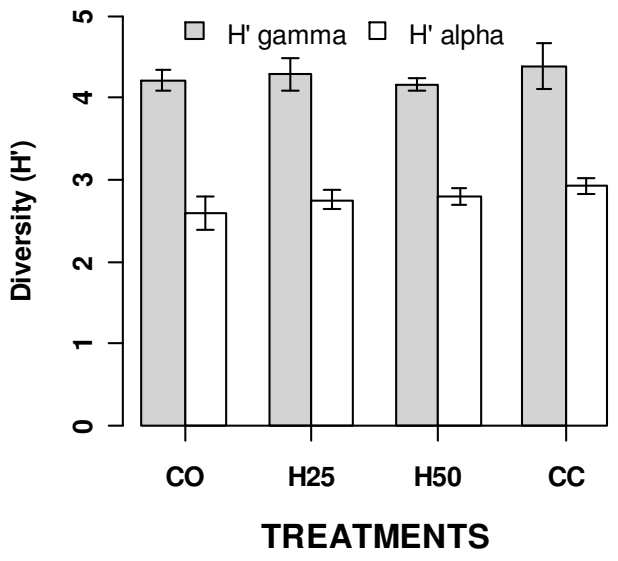

d)

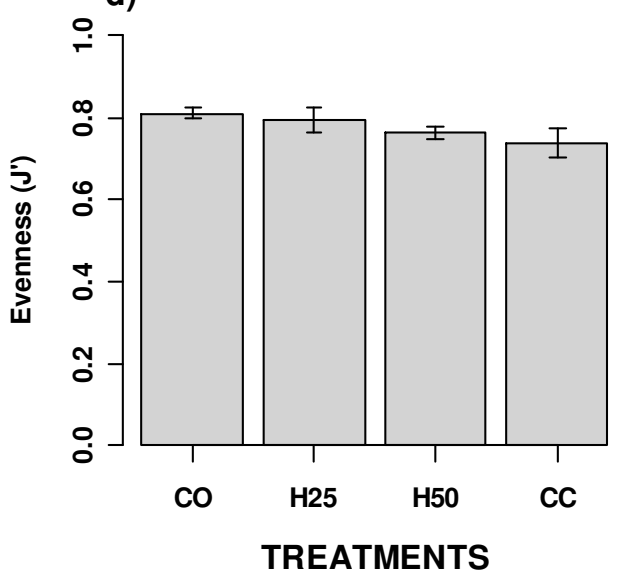

Figure 3. Comparison of different richness (a), Shannon diversity (b), heterogeneity (c) and evenness (d) values among treatments (mean $\pm \mathrm{SE}$ ). See Methods or Figure 1 caption for treatment description. Different letters above the bars indicate significant differences among treatments $(p<0.05)$ by Tukey's test.

\subsection{Relationship between variables}

The correlation analysis carried out to determine the relationship among the 13 variables analyzed (Table 1) showed that basal area, canopy cover and $P$. pinaster seedlings were negatively correlated with different richness values $\left(S, S_{\alpha}\right.$ and $\left.S_{\beta}\right)$, as well as to the number of perennial and annual herbs. However, in general those parameters were not correlated with diversity values $\left(\mathrm{H}^{\prime}, \mathrm{H}_{\alpha}{ }_{\alpha}, \mathrm{H}_{\beta}{ }_{\beta}\right)$. The Shannon diversity ( $\mathrm{H}^{\prime}$ ) showed a significant positive correlation with $\mathrm{H}_{\alpha}{ }_{\alpha}, \mathrm{H}^{\prime}{ }_{\beta}$ and $\mathrm{J}$ ', and with the number of perennial herbs and woody species. The number of $P$. pinaster seedlings was negatively correlated with annual species number and positively with basal area. 
The PCA performed for the joint comparison of all the variables produced an ordination of plots with the two first axes accounting for $78 \%$ of the total variance. The first component explained 55\% of variance and was strongly positively correlated with $\mathrm{S}, \mathrm{S}_{\alpha}, \mathrm{H}_{\alpha}$, and number of perennial and annual herbs, on the contrary it was strongly negatively correlated with basal area, canopy cover and number of $P$. pinaster seedlings (Table 2).

Table 1. Pearson correlation matrix between richness, diversity, functional groups richness (As: annual species number; Ps: perennial species number; Ws: woody species number), number of $P$. pinaster seedlings $(\mathrm{Pp})$, canopy cover $(\mathrm{Cc})$ and basal area $(\mathrm{Ba})$. In bold type significant correlations at $p<0.05$.

\begin{tabular}{|c|c|c|c|c|c|c|c|c|c|c|c|c|c|}
\hline & $\overline{S_{\gamma}}$ & $\mathrm{S}_{\alpha}$ & $\mathrm{S}_{\beta}$ & $\mathrm{H}_{\gamma}^{\prime}$ & $\mathrm{H}_{\alpha}^{\prime}$ & $\mathrm{H}_{\beta}^{\prime}$ & $\mathrm{J}^{\prime}$ & As & Ps & Ws & $\mathrm{Pp}$ & $\mathrm{Cc}$ & $\mathrm{Ba}$ \\
\hline$S_{\gamma}$ & 1 & & & & & & & & & & & & \\
\hline$S_{\alpha}$ & 0.85 & 1 & & & & & & & & & & & \\
\hline$S_{\beta}$ & 0.41 & -0.13 & 1 & & & & & & & & & & \\
\hline $\mathrm{H}_{\gamma}^{\prime}$ & 0.53 & 0.71 & -0.20 & 1 & & & & & & & & & \\
\hline $\mathrm{H}_{\alpha}^{\prime}$ & 0.60 & 0.83 & -0.30 & 0.66 & 1 & & & & & & & & \\
\hline $\mathrm{H}_{\beta}^{\prime}$ & 0.06 & 0.04 & 0.05 & 0.60 & -0.21 & 1 & & & & & & & \\
\hline J' & -0.32 & 0.00 & -0.57 & 0.63 & 0.15 & 0.66 & 1 & & & & & & \\
\hline As & 0.94 & 0.72 & 0.50 & 0.26 & 0.52 & -0.21 & -0.57 & 1 & & & & & \\
\hline Ps & 0.92 & 0.79 & 0.37 & 0.59 & 0.59 & 0.14 & -0.19 & 0.79 & 1 & & & & \\
\hline Ws & 0.46 & 0.54 & -0.07 & 0.72 & 0.33 & 0.58 & 0.42 & 0.28 & 0.36 & 1 & & & \\
\hline $\mathrm{Pp}$ & -0.67 & -0.73 & 0.01 & -0.26 & -0.65 & 0.35 & 0.38 & -0.72 & -0.55 & 0.03 & 1 & & \\
\hline $\mathrm{Cc}$ & -0.83 & -0.52 & -0.69 & -0.19 & -0.29 & 0.06 & 0.55 & -0.86 & -0.79 & -0.12 & 0.50 & 1 & \\
\hline $\mathrm{Ba}$ & -0.86 & -0.59 & -0.61 & -0.19 & -0.40 & 0.18 & 0.58 & -0.90 & -0.81 & -0.10 & 0.60 & 0.98 & 1 \\
\hline
\end{tabular}

The second component explained an additional $23 \%$ and only showed positively correlation with diversity $\left(\mathrm{H}^{\prime}\right.$ and $\mathrm{H}_{\beta}{ }_{\beta}$ ), evenness $\left(\mathrm{J}^{\prime}\right)$ and woody species number (Table 2). In the ordination diagram, the first axis ordered the sites according to their treatment, increasing harvest intensity from the left to the right hand (Fig. 4). Controls (CO) were located on the left hand associated with greater basal area and lower richness. Close plots (H25) were located near controls and open plots (H50) in intermediate position. However, clear cuts (CC) appeared on the right hand without basal area and greater species number. The second axis was related to diversity gradient, increasing diversity, evenness and woody species number to the positive end, and produced a separation between plots within the same treatment.

\section{DISCUSSION}

The results illustrate that three harvest treatments applied over a natural stand of Maritime pine in Spain influenced on species richness, annual herbs and woody species cover, and reduced the number of $P$. pinaster seedlings. These results were in agreement with previous studies that have documented how overstory alterations conditioned the post-disturbance response of understory vegetation (Ramovs \& Roberts 2003). 
Table 2. Correlation coefficients of plot scores along axes 1 and 2 and the 13 variables used in the principal components analysis (PCA). In bold type significant correlations at $p<0.01$.

\begin{tabular}{lcc}
\hline & Axis 1 & Axis 2 \\
\hline $\mathrm{S}_{\gamma}$ & $\mathbf{0 . 9 8}$ & 0.12 \\
$\mathrm{~S}_{\alpha}$ & $\mathbf{0 . 8 2}$ & 0.46 \\
$\mathrm{~S}_{\beta}$ & 0.43 & -0.55 \\
$\mathrm{H}_{\gamma}{ }_{\gamma}$ & 0.45 & $\mathbf{0 . 8 7}$ \\
$\mathrm{H}_{\alpha}{ }^{\prime}$ & $\mathbf{0 . 6 1}$ & 0.46 \\
$\mathrm{H}^{\beta}$ & -0.06 & $\mathbf{0 . 6 5}$ \\
$\mathrm{J}^{\prime}$ & -0.41 & $\mathbf{0 . 8 7}$ \\
Annual species number & $\mathbf{0 . 9 6}$ & -0.16 \\
Perennial herbs species number & $\mathbf{0 . 9 0}$ & 0.18 \\
Woody species number & 0.32 & $\mathbf{0 . 7 2}$ \\
Number of Pinus pinaster seedlings & $\mathbf{- 0 . 7 4}$ & 0.04 \\
Canopy cover & $\mathbf{- 0 . 8 8}$ & 0.28 \\
Basal area & $\mathbf{- 0 . 9 3}$ & 0.29 \\
& & \\
Eigenvalues & 8.17 & 3.47 \\
Explained variance & $55 \%$ & $23 \%$ \\
\hline
\end{tabular}

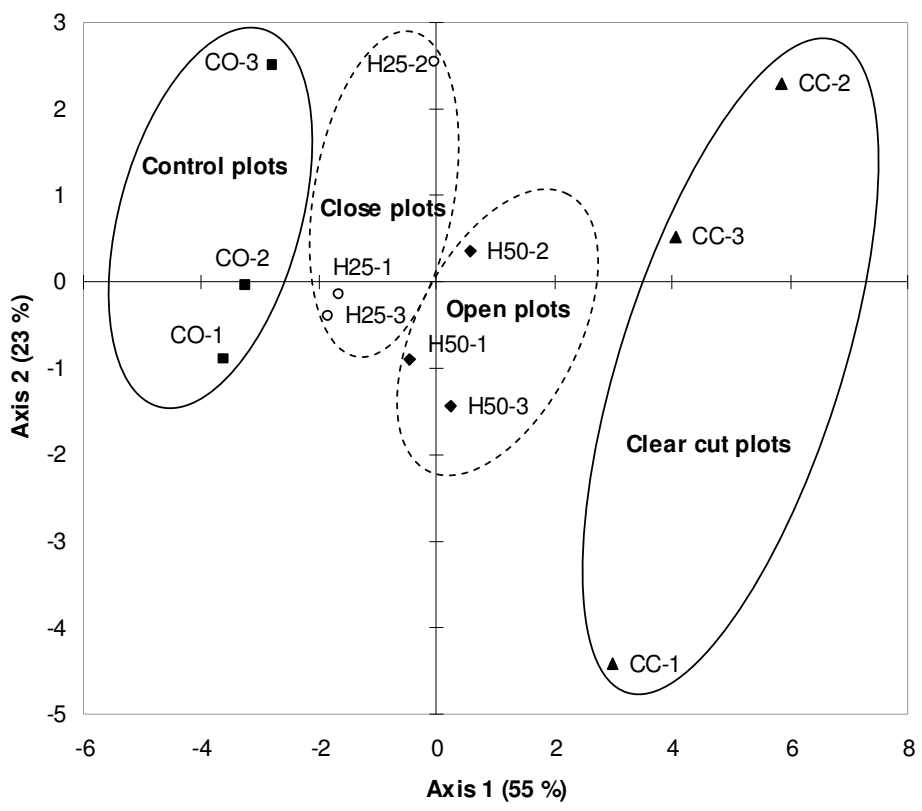

Figure 4. First two axes of the PCA ordination of different harvest intensity plots. See Methods or Figure 1 caption for treatment description. The number after the treatment abbreviation indicates the number of replicate.

\subsection{P. pinaster seedlings}

An important result was that the three harvest intensities reduced the number of $P$. pinaster seedlings in comparison with control plots; thus the first hypothesis is accepted. The reduction in the number of established seedlings from control to clear cut 
plots was correlated positively with basal area and negatively with annual species number. Therefore, this reduction may be caused by a combination of factors: (1) a decrease of seed inputs caused by the elimination of trees in treated plots in comparison with controls; (2) a reduction of canopy cover, which undoubtedly changed understory microclimate (Aussenac 2000), increasing the radiation intensity during summer and reducing the water availability for seedlings and their viability (Castro et al. 2004; Gómez-Aparicio et al. 2005; Calvo et al. 2008) and (3) competition for water and nutrients between coniferous seedlings and annual species (Peltzer et al. 2000), since annuals were able to dry up the upper soil layer leading to seedling mortality, especially during the early period of seedling development (Sternberg et al. 2001). Indeed, those factors could be highly emphasized by the intense summer droughts detected in the study area at 2004-2006 periods. Especially over treated plots, because temperature and moisture stress are lower in the presence of an overstory cover (Pérez \& Moreno 1998; Aussenac 2000). The relative importance of each of these possible explanations required further investigation.

In any case, the density of seedlings found in this stand three years after harvest is very low, even in controls (3.3 seedlings $\left./ \mathrm{m}^{2}\right)$, compared with 8 seedlings $/ \mathrm{m}^{2}$ recommended to ensure natural regeneration (Luis-Calabuig et al. 2002). Therefore, artificial reintroduction of seeds or seedlings may be a suitable option to increase the seedling density (Pausas et al. 2004), with the objective of facing up to the survival loss caused by inter-specific competition (Eshel et al. 2000), and water availability by summer droughts (Gómez-Aparicio et al. 2005), which would become normal in this area in near future as a consequence of climate change (Intergovernmental Panel on Climate Change (IPCC) 2007).

\subsection{Functional groups (life forms)}

The harvest treatments, in comparison with controls, influenced the richness of annual and perennial herbs and plant cover of annual herbs and woody species, thus the second hypothesis is partially accepted.

Different studies have reported that harvesting increases potential growing space in the understory (Newmaster et al. 2007), and the relative availability of resources (Fredericksen et al. 1999), especially light (Zenner et al. 2006), improving the conditions for establishment of early colonizer species (Newmaster et al. 2007). Not 
surprisingly, our results provided similar patterns, with an increase of annual species richness and cover along the harvest intensity gradient (from controls to clear-cuts).

In these semi-arid Mediterranean forests, with three months of summer drought, harvesting generates habitats with a strong seasonal stress and with understory vegetation dominated by annuals. Under these conditions, perennial species establish themselves with difficulty compared to annuals whose life cycle is adapted to this seasonal stress (Madon \& Médail 1997). At the same time, and as we said previously, the pine seedling establishment may be reduced by the great cover development of annual species through inter-specific competition (Eshel et al. 2000).

On more disturbed plots (clear-cut), with greater solar radiation intensity during summer, species richness of perennial herbs showed greater values than on control plots. This may be caused because the new established species were characteristic of Mediterranean open sites (e.g. Cynodon dactylon or Armeria arenaria), in accordance with previous research findings in recent clear-cut stands (Roberts \& Gilliam 1995; North et al. 1996).

Woody species showed an opposite pattern, maintaining their species richness and decreasing in cover along the harvest intensity gradient (from controls to clearcuts). Woody species were more abundant in sites with higher tree cover, as in control and close (H25) plots, than in clear-cut and open (H50) plots. It is possible that the partial shade provided by trees may alleviate the harsh environmental factors prevailing under full-sun environments (Alrababah et al. 2007), enhancing the woody species growth. However, under the most severe treatments, although woody species richness was similar to control plots, the physical destruction of existing woody species by the harvest operations (Newmaster et al. 2007), linked to the marked seasonal stress may cause their cover reduction.

The different responses of annual and perennial herbs, and woody species richness along the harvest treatments supports the hypothesis of Peet's (1978), who found different response patterns of plant species richness for different structural groups (woody and herbs).

\subsection{Richness and diversity}

The influence of harvest is clear only in the case of richness; therefore the third hypothesis is partially accepted. Three years after harvesting, understory plant richness 
was higher in treated plots than in controls, although differences were significant only for the most severe disturbance treatment (clear-cutting). At the same time, plant richness had negatively significant relationship with basal area, suggesting an increase in richness as harvest intensity increases, as observed in similar studies in temperate forest (Fredericksen et al. 1999; Götmark et al. 2005; Zenner et al. 2006). Harvesting increased species richness because of the colonization of annuals and some perennial herbs (Swindel et al. 1983; Götmark et al. 2005), which were favored by the modification of the stand habitat-conditions (Jobidon 1990).

Despite the positive influence of harvesting on species richness showed in this study, no differences with control plots on the understory Shannon diversity values were found, as in other studies in temperate forest (Gilliam et al. 1995; Gilliam 2002; Krzic et al. 2003). The relative high Shannon diversity values reached under all treatments indicated that plant communities after harvesting were not dominated by just a few species (Krzic et al. 2003). On the contrary, these results did not suggest that an increase in harvest intensity did not influence the understory species layer. Peltzer et al. (2000) found that plant diversity did not change when increasing the intensity of silvicultural disturbances, but a higher number of herb species appeared. These results are consistent with our findings of increasing annual and perennial herbs richness with harvest intensity. The Shannon index ( $\left.\mathrm{H}^{\prime}\right)$ is affected by species richness and evenness (Westman 1990). As previously explained, richness increased as harvest intensity increases, whereas evenness decreased, resulting in no changes in the Shannon diversity index ( $\left.H^{\prime}\right)$. This suggest that in control plots the relative abundance of species is more similar than in treated plots (H25, H50 and CC), in which some of new species tend to be relatively uncommon or rare (Small \& McCarthy 2002).

The separation between different harvest treatments was clearly connected with basal area, canopy cover and $P$. pinaster seedlings reduction, and with the increase of richness $\left(S\right.$ and $S_{\alpha}$ ) and herbs richness (annual and perennial). This indicates that the elimination of tree cover favoured the establishment of new herbs species, which increased their cover by the addition of more species, rather than by the growth increase of a few of them (Gilliam 2002). In contrast, diversity ( $\mathrm{H}^{\prime}$ and $\mathrm{H}^{\prime}{ }_{\beta}$ ), evenness and woody species number were related with differences between plots of the same treatment, rather than with differences between harvest treatments. These results emphasize the difficulty in making general conclusions of the effects of harvest 
treatments (disturbances) on diversity, supporting the conclusions of Gilliam (2002) and Tárrega et al. (2006).

\section{CONCLUSIONS}

Our results emphasize that the tree harvest treatments assessed are not suitable for the management of this $P$. pinaster stand. Otherwise, the reduction of pine seedling density and the changes in richness and cover of functional groups by harvest treatments would not induce the natural regeneration of this stand, maintaining the understory plant layer. Managers must realize that even controls would have problems to ensure natural regeneration, because the pine seedling density reached in three years is not enough to guarantee it. Therefore, further investigations are needed to assess seedling establishment limiting factors, the effectiveness of reintroduction of pine seeds or seedlings and other silvicultural alternatives (i.e. single tree selection or nurse plant strategies) to achieve adequate management practices, including wood production, with respect to ecosystem functioning.

\section{ACKNOWLEDGEMENTS}

We thank Sonia García-Muñoz, Cristobal Ordóñez and Ana I. de Lucas for fieldwork assistance, and Pilar Zaldívar for species nomenclature assistance. This study was supported by a grant from the Basque-Country Government to Josu González Alday (BFI06.114), and Research Projects from the Spanish Science National Program (codes AGL2001-1780 and AGL2004-07094-C02-02/FOR) to Felipe Bravo.

\section{REFERENCES}

Alía, R., Martín, R., de Miguel, J., Galera, R.M., Agúndez, D., Gordo, J., Salvador, L., Catalán, G. \& Gil, L.A. 1996. Regiones de procedencia Pinus pinaster Ait. DGCN, Madrid, Spain.

Alrababah, M.A., Alhamad, M.A., Suwaileh, A. \& Al-Gharaibeh, M. 2007. Biodiversity of semi-arid Mediterranean grasslands: Impact of grazing and afforestation. Applied Vegetation Science 10: 257-264.

Aussenac, G. 2000. Interactions between forest stands and microclimate: ecophysiological aspects and consequences of silviculture. Annals of Forest Science 57: $287-301$. 
Bravo-Oviedo, A., del Río, M. \& Montero, G. 2007. Geographic variation and parameter assessment in generalized algebraic difference site index modelling. Forest Ecology Management 247: 107-119.

Calvo, L., Santalla, S., Valbuena, L., Marcos, E., Tárrega, R. \& Luis-Calabuig, E. 2008. Post-fire natural regeneration of Pinus pinaster forest in NW Spain. Plant Ecology 197: 81-90.

Castro, J., Zamora, R., Hódar, J.A. \& Gómez, J.M. 2004. Seedling establishment of boreal tree species (Pinus sylvestris) at its southern most distribution limit: consequences of being in a marginal Mediterranean habitat. Journal of Ecology 92: 266-277.

Decocq, G., Aubert, M., Dupont, F., Alard, D., Saguez, R., Wattez-Franger, A., De Foucault, B., Delelis-Dusollier, A. \& Bardat, J. 2004. Plant diversity in a managed temperate deciduous forest: understorey response to two silvicultural systems. Journal of Applied Ecology 41: 1065-1079.

Eshel, A., Henig-Sever, N. \& Ne'eman G. 2000. Spatial variation of seedling distribution in an east Mediterranean pine woodland at the beginning of post-fire succession. Plant Ecology 148: 175-182.

Fahey, R.T. \& Puettmann, K.J. 2007. Ground-layer disturbance and initial conditions influence gap partitioning of understorey vegetation. Journal of Ecology 95: 10981109.

Fredericksen, T.S., Ross, B.D., Hoffman, W., Morrison, M.L., Beyea, J., Johnson, B., Lester, M.B. \& Ross, E. 1999. Short-term understory plant community responses to timber-harvesting intensity on non-industrial private forestlands in Pennsylvania. Forest Ecology and Management 116: 129-139.

Gilliam, F.S. 2002. Effects of harvesting on herbaceous layer diversity of a central Appalachian hardwood forest in West Virginia, USA. Forest Ecology and Management 155: 33-43.

Gilliam, F.S., Turril, N.L. \& Adams, M.B. 1995. Herbaceous-layer and overstory species in clear-cut and mature Appalachian hardwood forests. Ecological Applications 5: 947-955.

Gómez-Aparicio, L., Gómez, J.M., Zamora, R. \& Boettinger, J.L. 2005. Canopy vs. soil effects of shrubs facilitating tree seedlings in Mediterranean montane ecosystems. Journal of Vegetation Science 16: 191-198. 
Götmark, F., Paltto, H., Norden, B. \& Götmark, E. 2005. Evaluating partial cutting in broadleaved temperate forest under strong experimental control: Short-term effects on herbaceous plants. Forest Ecology and Management 214: 124-141.

Halpern, C.A. \& Spies, T.A. 1995. Plant species diversity in natural and managed forests of the Pacific Northwest. Ecological Applications 5: 913-934.

Härdtle, W., von Oheimb, G. \& Wesphal, C. 2003. The effects of light and soil conditions on the species richness of the ground vegetation of deciduous forest in northern Germany (Schleswig-Holstein). Forest Ecology and Management 182: 327-338.

Hughes, J.W. \& Fahey, T.J. 1991. Colonization dynamics of herbs and shrubs in a disturbed northern hardwood forest. Journal of Ecology 79: 605-616.

Hummel, S.S. 2003. Managing structural and compositional diversity with silviculture. In: Monserud, R.A., Haynes, R.W. \& Johnson, A.C. (eds.) Compatible forest management, pp. 85-120. Kluwer Academic Publishers, the Netherlands.

Intergovernmental Panel on Climate Change (IPCC). 2007. The physical science basis. Cambridge University Press, New York, USA.

Jobidon, R. 1990. Short-term effect of three mechanical site preparation methods on species diversity. Tree Planters Notes 41: 39-42.

Junta de Castilla y León. 1988. Análisis del medio físico de Segovia. EPYPSA, Valladolid, Spain.

Kimmins, J.P. 2004. Forest ecology: a foundation for sustainable forest management and environmental ethics in forestry. Prentice Hall, NJ, USA.

Krebs, C.J. 1999. Ecological methodology. Addison-Welsey Educational Publishers, Menlo Park, CA, USA.

Krzic, M., Newman, R.F. \& Broersma, K. 2003. Plant species diversity and soil quality in harvested and grazed boreal aspen stands of northeastern British Columbia. Forest Ecology and Management 182: 315-325.

Luis-Calabuig, E., Torres, O., Valbuena, L., Calvo, L. \& Marcos, E. 2002. Impact of large fires on a community of Pinus pinaster. In: Trabaud, L. \& Prodon, R. (eds.) Fire and biological processes, pp. 1-12. Backhuys Publishers, Leiden, Netherlands.

M.A.P.A. 1987. Caracterización agroclimática de la provincia de Segovia. Ministerio de Agricultura Pesca y Alimentación, Madrid, Spain.

Madon, O. \& Médail, F. 1997. The ecological significance of annuals on a Mediterranean grassland. Plant Ecology 129: 189-199. 
Magurran, A.E. 2004. Measuring biological diversity. Blackwell Publishing, oxford, UK.

Margalef, R. 1972. Homage to Evelyn Hutchinson, or why is there an upper limit to diversity. Transactions of Connecticut Academy of Arts and Sciences 44: 211-235.

Nagai, M. \& Yoshida, T. 2006. Variation in understory structure and plant species diversity influenced by silvicultural treatments among 21- to 26-year-old Picea glehnii plantations. Journal of Forest Research 11: 1-10.

Newmaster, S.G., Parker, W.C., Bell, F.W. \& Paterson, J.M. 2007. Effects of forest floor disturbances by mechanical site preparation on floristic diversity in a central Ontario clear-cut. Forest Ecology and Management 246: 196-207.

North, M., Chen, J., Smith, G., Krakowiak, L. \& Franklin, J. 1996. Initial response of understory plant diversity and overstory tree diameter growth to a green tree retention harvest. Northwest Science 70: 24-35.

Oria de Rueda, J.A. 2003. Guía de los árboles y arbustos de Castilla y León. Calamo, Palencia, Spain.

Pausas, J.G., Bladé, C., Valdecantos, A., Seva, J.P., Fuentes, D., Alloza, J.A., Vilagrosa, A., Bautista, S., Cortina, J. \& Vallejo, R. 2004. Pines and Oaks in the restoration of Mediterranean landscapes of Spain: New perspectives for an old practice-a review. Plant Ecology 171: 209-220.

Peet, R.K. 1978. Forest vegetation of the Colorado Front Range: pattern of species diversity. Vegetatio 37: 65-78.

Peltzer, D.A., Bast, M.L., Wilson, S.D. \& Gerry, A.K. 2000. Plant diversity and tree responses following contrasting disturbances in boreal forest. Forest Ecology and Management 127: 191-203.

Pérez, B. \& Moreno, J.M. 1998. Fire-type and forestry management effects on the early postfire vegetation dynamics of a Pinus pinaster woodland. Plant Ecology 134: 2741.

Pielou, E.C. 1969. An introduction to mathematical ecology. Willey, New York, USA.

R Development Core Team. 2008. R: A language and environment for statistical computing. R Foundation for Statistical Computing, Vienna, Austria. ISBN 3900051-07-0, URL: http://www.R-project.org.

Ramovs, B.V. \& Roberts, M.R. 2003. Understory vegetation and environment responses to tillage, forest harvesting, and conifer plantation development. Ecological Applications 13: 1682-1700. 
Roberts, M.R. \& Gilliam, F.S. 1995. Patterns and Mechanisms of plant diversity in forested ecosystems: implications for forest management. Ecological Applications 5: 969-977.

Scarascia-Mugnozza, G., Oswald, H., Piussi, P. \& Radoglou, K. 2000. Forests of the Mediterranean region: gaps in knowledge and research needs. Forest Ecology and Management 132: 97-109.

Shannon, C.E. \& Weaber, W. 1949. The mathematical theory of communication. University of Illinois Press, Urbana, USA.

Small, J.C. \& McCarthy, B.C. 2002. Spatial and temporal variability of herbaceous vegetation in an earstern deciduous forest. Plant Ecology 164: 37-48.

Sternberg, M., Danin, A. \& Noy-Meir, I. 2001. Effects of clearing and herbicide treatments on coniferous seedling establishment and growth in newly planted Mediterranean forests. Forest Ecology and Management 148: 179-184.

Swindel, B.F., Conde, L.F. \& Smith, J.E. 1983. Plant cover and biomass response to clear-cutting, site preparation, and planting in Pinus elliottii flatwoods. Science 219: 1421-1422.

Tárrega, R., Calvo, L., Marcos, E. \& Taboada, A. 2006. Forest structure and understory diversity in Quercus pyrenaica communities with different human uses and disturbances. Forest Ecology and Management 227: 50-58.

Westman, E.W. 1990. Managing for biodiversity: unresolved science and policy questions. Bioscience 40: 26-33.

Zar, J.H. 1996. Biostatistical analysis, London. UK.

Zenner, E.K., Kabrick, J.M., Jensen, R.G., Peck, J.E. \& Grabner, J.K. 2006. Responses of ground flora to a gradient of harvest intensity in the Missouri Ozarks. Forest Ecology and Management 222: 326-334. 